\title{
THE PROBLEM FIELD OF CALENDARS IN DIFFERENT CULTURES
}

\author{
Günter Graumann \\ University of Bielefeld•graumann@mathematik.uni-bielefeld.de
}

\begin{abstract}
Following my presentation of the last ProMath conference I like to present this year another problem field connected with astronomy namely calendars. With a calendar we all are confronted permanent and think of our calendar as a matter of course. But in our global connected world we also hear from other calendars or rhythms, especially in the context of religion. So it is good for children at school to get to know about the background of calendars as well as to fight with problems within the field of calendars. First of all we have to collect astronomical facts and the origin of different calendars. With this we also can see how the problem of time units which are not whole numbers can be brought into special rhythms of whole numbers and how this was managed in history. Moreover we can find out that any rational number can be presented in a rhythm of whole numbers. Secondly we can compute with the Islamic calendar which is a pure moon-calendar and find out why and in which way the Islamic celebrations move in our solar calendar. Furthermore we will discuss the Christian festivities and its differences in catholic/protestant churches and the Russian-orthodox church. Especially we have to work on the problem of determining the date of Easter (the "computus ecclesius" as it was named in the middle ages). Finally we can have a look at the division of the whole world into time zones as well as different phases of the moon and the angular velocity of moon and stars in the night.
\end{abstract}

\section{Introduction}

In school children are confronted with calendars first in grade two in connection with the theme "time" and "timepiece". Then they learn names and length of months, investigate changes by walking in a calendar of a month, count days or weeks from one date to another (e.g. from today to birthday or to Christmas etc.) and notice that (in the $20^{\text {th }}$ and $21^{\text {st }}$ century) every fourth year the February has 29 days instead of 28 days in the other years.

In this paper the background of our calendar and other calendars as well as some effects of these calendars will be discussed. So in the following we will focus on problems which are adequate for pupils of grade 5 and beyond.

First of all the pupils have to pick up (in books or in the internet) some knowledge about astronomical facts and the origin of different calendars. Then there will come up several problems which can be broadened by the pupils according to the request of the pupils or at a given later time.

In this paper different problem fields according to calendars are just characterized to inspire and support teacher to handle with this theme in school. Special methodical consideration will be discussed only casually because the realization in class depends on the situation in each case and only the teaching person can assess this. Moreover it is wellknown that meticulous elaborated teaching units are not used in the way of the given plan. 


\section{Basic information about calendar and time periods}

First of all: "A calendar is a system of organizing days for social, religious, commercial or administrative purposes. This is done by giving names to periods of time, typically days, weeks, months, and years. A date is the designation of a single, specific day within such a system. Periods in a calendar (such as years and months) are usually, though not necessarily, synchronized with the cycle of the sun or the moon." (http://en.wikipedia.org/wiki/Calendar)

So in different era and regions men invented different calendars which could fit to astronomical rhythms in some degree. The astronomical facts one has to deal with are the following ones:

- Hour, Minute, Second: In ancient times the period from sunrise to sunset was divided into 12 hours. This delivers different spans in summer and winter. In the late middle age when times periods became import for travel, trade and economy one equalized the measure of one hour by using the day of the equinox, i.e. one revolution of the earth was divided by 24 so that today 1 hour is the 24th part of one day.

Referring to the sexagesimal number system of the old Babylonians (which e.g. Ptolemy used for astronomical calculations) a minute (lat. "hora minuta prima" - first reduced part) was defined as $6 \boldsymbol{o}^{\text {th }}$ part of a hour.

In the same way a second (lat. "hora minuta secunda" - secondly reduced part) was defined as $6 \boldsymbol{o}^{\text {th }}$ part of a minute or $3600^{\text {th }}$ part of a hour.

In Physics one also uses: Millisecond $\left(1 \mathrm{~ms}=10^{-3} \mathrm{~s}\right), \quad$ Mikrosecond $(1 \mu \mathrm{s}=$ $\left.10^{-6} \mathrm{~s}\right), \quad$ Nanosecond $\left(1 \mathrm{~ns}=10^{-9} \mathrm{~s}\right), \quad$ Pikosecond $\left(1 \mathrm{ps}=10^{-12} \mathrm{~s}\right)$, Femtosecond ( $\left.1 \mathrm{fs}=10^{-15} \mathrm{~s}\right), \quad$ Attosecond $\left(1 \mathrm{as}=10^{-18} \mathrm{~s}\right)$. The attosecond is the minimum time period one can measure today (first it was measured at the University of Bielefeld some years ago). Because length units are defined by time multiplied with the velocity of light the measurement of attoseconds generates exact length measurements in the rage of nanometer.

- Day: This is the time for one revolution of the earth around her axis. Scientists differentiate between the "Solar Day" (which is our normal day) and the "Stellar Day".

A Solar Day is measured as one revolution of the earth in respect to the sun from a special point of the earth, i.e. we measure the time difference between two consecutive equal positions of the sun (mostly highest point in the south or the opposite at midnight). Because the earth is moving on her orbit around the sun the revolution is not exact a $360^{\circ}$-revolution but a little bit more. And because the motion of the earth on its orbit around the sun is not always constant (the orbit is an ellipse near a circle but not a circle) the momentary solar day is $24 \mathrm{~h} \pm 30$ s. So 24 hour is the mean value. This solar day is the basis for all calendars. 
A Stellar Day measures the revolution in respect to a fixed star (a fixed direction in the space). It is a little bit shorter than a Sun-Day (about 4 minutes equal to $1 / 365$ of a Sun-Day).

- Week: This is defined in respect to bible data as 7 days. This is not conditioned by astronomical data.

- Month: This is the average time for one revolution of the moon around the earth. Scientists differentiate between the "Synodical Month" or "Lunation" (which is our normal basis for an astronomical month) and the "Siderial Month" or "Stellar Month" and the "Anomalic Month".

A Lunation (Synodical Month or just Month) is the average period of two consecutive equal moon phases (like full moon or new moon) seen from one point of the earth. Its enlargement is $\mathbf{2 9 . 5 3 0 5 9}$ days (solar days) or $29 \mathrm{~d}+12 \mathrm{~h}$ $+44 \mathrm{~m}+3 \mathrm{~s}$. Because the earth with its somewhat elliptic orbit around the sun does have different velocities the period of lunation fluctuates, a single lunation ranges between $29.27 \mathrm{~d}$ and $29.83 \mathrm{~d}$ with 29.53059 days as mean value.

A Stellar Month (Siderial Month) is the average time for one revolution around the earth in respect to one direction in the space (e.g. one fixed star like Sirius). A siderial month is about two days shorter than a synodical month because in one month the earth moves on its orbit around the sun about 1/12 back. A stellar month takes 27.322 days in the mean.

An Anomalic Month is the period of the cycle period on the path of the moon (e.g. the period of two consecutive moments of the perigee, the nearest point to earth).

- Year: This is the period of one orbit time of the earth around the sun. Scientists differentiate between the "Tropic Year" or "Solar Year" (which is the basis for almost all calendars) and the "Siderial Year" or "Stellar Year" and the "Anomalic Year".

A Solar Year (Tropical Year or just Year) is the period from one spring equinox to the next one. Its enlargement is $\mathbf{3 6 5 . 2 4 2 2 0}$ days or $365 \mathrm{~d}+5 \mathrm{~h}+$ $48 \mathrm{~m}+46 \mathrm{~s}$.

A Stellar Year (Siderial Year) is the period of revolution of the earth around the sun in respect to one direction in the space (e.g. one fixed star like Sirius). The period time is about 20 minutes longer than a sun year because of the rotation of its axis (precession-nutation). Its average enlargement is 365,25636 days $(365 d+6 h+9 m+10 s)$.

An Anomalic Year is the period of the cycle period on the path of the earth (e.g. the period of two consecutive moments of the perigee, the nearest point to the sun). 
Hint concerning accurateness of measurements: Because of rotations of the axis of the earth (nutation) the period of a year fluctuates within 18 year about 18 seconds the above given accurateness $( \pm$ o.oooo1d or \pm 1 s) cannot be used more detailed. The same accurateness is true for almost all other dimensions.

\section{Different calendars with corresponding problems}

In human history we can find about three different types of calendars: moon calendars, sun calendars and moon-sun-calendars (at which the last one tries to harmonize the rhythms of moon and year periods).

\section{Moon calendars}

The presumable oldest calendars are moon calendars because it gave manageable spans and the phases of the moon is quite good observable.

Most moon calendars work with a period time of alternating 29 days and 30 days (i.e. an average length of 29.5 days). The difference to the astronomical period of 29.53059 days is 0.03059 days $(44 \mathrm{~m}+3 \mathrm{~s})$ and will come up with about one day in 33 moon orbits. Therefore some moon calendars in a special rhythm of some months have one day more.

E.g. in the calendar of Islamic religion in a cycle of 30 Islamic years (with 360 months) the $2^{\text {nd }}, 5^{\text {th }}, 7^{\text {th }}, 10^{\text {th }}, 13^{\text {th }}, 16^{\text {th }}, 18^{\text {th }}, 21^{\text {th }}, 24^{\text {th }}, 26^{\text {th }}$ and $29^{\text {th }}$ year is a leap year with one day more. In a normal Islamic year the months with odd number have 30 days while those with even numbers have 29 days. But in a leap year the $12^{\text {th }}$ month does have 30 days.

Problems in the frame of moon calendars:

- Suppose that we have a moon calendar with just alternating 30 and 29 days length (i.e. an average length of exact 29.5 days); How many days long is a period of 12 such months and what is the date of the start of the second resp. third resp. forth 12-month-period in our calendar if we start the first period on January $1^{\text {st }} 2014$ ? [Answer: 354 days / December $21^{\text {st }} 2014$ resp. December $10^{\text {th }} 2015$ resp. November $28^{\text {th }} 2016$ ].

- In which next coming year of our calendar are two starts in a year as in 2014 with such calendar of a 12-month-period? [2045: January 6th and December 26th].

- On January 1st 2014 we have new moon; at what date do we have new moon in January 2015 resp. 2016? (Use the astronomical length of a month.) [20th resp. 9th].

- Compute the average length of an Islamic month and compare it with the astronomical length of a month.

$[(360 \cdot 29.5 d)+11 d=10631 d$ and $10631 d: 360=29.530556$ days $/ 29.530556-29.53059$ $=0.0000344$ days $]$.

- How many days/months/years are needed until this difference comes up to almost one day? [858453 days / 29070 Islamic months / 24221/2 Islamic years]. 
- How many sun years make almost one day difference between the average Islamic month and the astronomical month? [2350 sun years].

Hint concerning types of data for the pupils: If the pupils did not work with decimals before then they can compute with days/hours/minutes/seconds. In higher grades they should first compute with decimals but also train the changes to days/hours/minutes /seconds.

\section{Sun calendars}

The oldest known sun calendar one did find in Egypt more than 5000 years ago. The yearly coming overflow of the Nile was the background. The Egyptians in the antiquity named three seasons (overflow, sowing, harvest) and the begin of the overflow was determined with help of the star Sirius (bright fix star in Egypt - called "Sothis" which means Bringer of the Nile or Renovator of the year).

Caesar then brought the sun calendar to Rome and to us (called Julian Calendar). In this calendar a normal year has 365 days and every fourth year there is a leap year with 366 days. Thus in average a Julian year has 365.25 days. The months of such a year are no longer in correspondence with the astronomical moon rhythm.

In 1582 the pope Gregory XIII'th decreed a new calendar (later on called Gregorian Calendar) starting from Oktober $4^{\text {th }} 1582$ in all catholic countries because in the Julian calendar in some hundreds of years the equinoxes changed the date. Later on also protestant countries and in stages also many other countries adapted this calendar which is the civil calendar round the world today. In the Gregorian calendar the dates October 1582 from $5^{\text {th }}$ to $14^{\text {th }}$ are deleted, so that after the October $4^{\text {th }} 1582$ the next day is October $15^{\text {th }}$ 1582. Moreover in future the leap day each year with a number that is divisible by 100 but not by 400 (so e.g. 1700, 1800, 1900) is deleted. Thus in average a Gregorian year has 365.2425 days.

Problems in the frame of the Julian and Gregorian calendar:

- Compare the average length of a Julian resp. Gregorian year with the astronomical sun year. [Difference: 0.0078 days $(11 \mathrm{~m}+14 \mathrm{~s})$ resp. 0.0003 days $(26 \mathrm{~s})$ ].

- In how many years accumulates this difference almost to 1 day? [128 years / 3333 years].

- The Julian calendar was renewed in $300 \mathrm{AD}$; how many days have been accumulated from 300 to 1582 as difference between the Julian calendar and the astronomical sun year rhythm? [10 days].

- How many days have been accumulated between the Julian calendar and the Gregorian calendar from 300 until today (note that until 1581 the Julian and Gregorian calendars don't differ)? [13 days].

- In 2014 January $1^{\text {st }}$ was a Wednesday. On which day of the week is January $1^{\text {st }}$ in 2015 resp. 2016 resp. 2017? [Thursday resp. Friday resp. Sunday]. 
- The planet Mars has a "day"(one circulation around his axis) of 24.65 hours and a sun year of 779.94 days $(779.94 \cdot 24=18718.56$ hours); find an acceptable rhythm with leap years for the Mars year in respect to the Mars day. [ $18718.56: 24.65=$ $759.37363 \approx 759.375 / 0.375=3 / 8$; therefore in a period of 8 Mars years we will have five of length 759 Mars days and three of length 760 Mars days, so every 72th Mars year one leap day has to be deleted].

Problems with representing rational numbers in a rhythm of whole numbers:

- Each rational number we can change into a rhythm of whole numbers like the rhythms in calendars with leap years. If we only look for numbers between o and 1 so in the Julian calendar we changed 0.25 into the rhythm o-o-o-1.

Find such rhythms for 0.75 resp. o.4 resp. 0.375 . [0-1-1-1 or 0-1-2 or 0-3 resp. 0-0-0-1-1 or 0-0-0-2 resp. 1-0-0-1-0-0-1-0 or 0-0-0-0-0-1-2 or 0-0-0-0-0-3 and all permutations of these series].

\section{Moon-sun-calendar}

A moon-sun-calendar one can find at the Jewish calendar. This is coming out with a rhythm of alternative 30 and 29 days as well as a cycle (called "Metonic Cycle") of 19 sun years (235 months) whereat the $3^{\text {rd }}, 6^{\text {th }}, 8^{\text {th }}, 11^{\text {th }}, 14^{\text {th }}, 17^{\text {th }}$ and $19^{\text {th }}$ year is a leap year with a $13^{\text {th }}$ month of 30 days. The start of this calendar is 3761 B.C. (supposed biblical Creation of the world). And every third year in this cycle the third months has 30 days (instead of 29) and sometimes the fourth month has only 29 days so that the average length of a month is almost the same as an astronomical month (difference less than $1 \mathrm{sec}$ ).

Problems in the frame of the Jewish calendar:

- Compute the average length of a year in a 19 year cycle. [235 $29,53059 \mathrm{~d}=$ $6939,68865 \mathrm{~d} / 6939,68865 \mathrm{~d}: 19=365,24677 \mathrm{~d}]$.

- What is the difference to an astronomical sun year and in what time does this difference accumulate to one day? [0.00457 days $(6 \mathrm{~m}+35 \mathrm{~s}) / 219$ years].

- How many days accumulated from the start of the Jewish calendar until now? $[(3761+2013) \cdot 0.00457$ days $=26.4$ days $]$.

- Approve that 235 synodic months and 19 sun years and 254 stellar months come up to same number of days (if you round to full days). [235.29.53059 $=6939.68865 \approx$ $6940 / 19 \cdot 365.2422=6939.6018 \approx 6940 / 254 \cdot 27 \cdot 322=6939.788 \approx 6940]$.

- Give an interpretation of this result. [After this period of 6940 days we have first that a special moon phase is almost in the same direction in space and on the same day of a year; e.g. in $2000 \mathrm{AD}$ we had full moon on spring equinox (equinox: Monday March 20 ${ }^{\text {th }}, 8: 35 \mathrm{MEZ}$ and full moon march 20 ${ }^{\text {th }}, 5: 44 \mathrm{MEZ}$ ) and this will come again in 6940 days respectively in $2019 \mathrm{AD}$ (equinox: Wednesday March $20^{\text {th }}$, 22:58 MEZ and full moon Thursday March 21 ${ }^{\text {st }}, 2: 43$ MEZ). Hint: The day of the week does change because only 6937 can divided by 7 without rest. Also the same day of the week one gets in $6939.7 \cdot 7$ days, that is 48578 days or 133 sun years.]. 


\section{Different calendars and religious data}

In the multicultural connected world of today even in one school we have pupils with different religious background. Thus it is import that all pupils at least know about the disparities of different religions and the main specialities of one religion.

The Islamic feasts are tied together with the Islamic calendar which has as rhythm an Islamic year of 12 months with 30 or 29 days (and summarized in a normal year 354 days resp. 355 days in a leap year). Therefore all data of Islamic feasts switch from year to year 10, 11 or 12 days back within the sun year (or Gregorian year). E.g. the start of Ramadan (fasting month for Muslims) resp. the Ramadan feast (Sugar feast) was in 2013 on July $28^{\text {th }}$ resp. August $8^{\text {th }}$ and will be in 2014 on June $28^{\text {th }}$ resp. July $27^{\text {th }}$ and in 2015 on June $18^{\text {th }}$ resp. July $17^{\text {th }}$.

Problems according to the Islamic calendar:

- The Islamic calendar started with the $1^{\text {st }}$ Muharram in the year Mohammed emigrated (from Mekka) to Medina, that is in the Julian calendar 622 July $16^{\text {th }}$. When did start the second resp. third Islamic Year? [623 July $5^{\text {th }}$ resp. 624 June $25^{\text {th }}$ (bear in mind that the $2^{\text {nd }}$ Islamic year is a leap year with 355 days)

- The first Ramadan ( $9^{\text {th }}$ month in the Islamic calendar) started on 623 March $9^{\text {th }}$. At what date started Ramadan in 624 resp. 625? [624 February $26^{\text {th }}$ resp. 625 February $\left.15^{\text {th }}\right]$.

- The Ramadan together with the three last months of an Islamic year takes 118 days. When does in 2014 start a new Islamic year? [2014 October $25^{\text {th }}$ ].

- The average length of an Islamic year is 354.367 days; how many Islamic years did pass until October $24^{\text {nd }}$ of 2014 ? [622 July $16^{\text {th }}$ to 2014 July $15^{\text {th }}$ are days $1392 \cdot 365$ $+(347-3)-10=508414$ and from July $16^{\text {th }}$ until October $24^{\text {nd }}$ are 98 days; total 508512 days; divided by 354.3671 makes 1435 Islamic years - on October $25^{\text {th }}$ in 2014 is new year for Moslems and the $1436^{\text {th }}$ year starts].

The Christmas feast is since about $350 \mathrm{AD}$ for all Christian denominations determined on December $25^{\text {th }}$ (with holy night on December $24^{\text {th }}$ in some countries). In 350 $\mathrm{AD}$ the crucifixion of Jesus as well as the conception of Maria was seen at the equinox (at that time March $25^{\text {th }}$ in the Julian calendar) so that the Nativity was determined nine month later on December $25^{\text {th }}$. This was also near the winter solstice so that the Christmas feast covered profane rites.

The Russian orthodox church until today uses the Julian calendar where the date of December $25^{\text {th }}$ (Julian calendar) is 13 days later in respect to the $25^{\text {th }}$ December of the Gregorian calendar (because of the 10 canceled days in 1582 and the canceled leap days 1700, 1800, 1900 in the Gregorian calendar). Therefore the Christmas feast in the Russian Orthodox Church is on January $7^{\text {th }}$ (of the Gregorian calendar) and the Russian orthodox feast of the three holy kings is on January $19^{\text {th }}$ (of the Gregorian calendar). 
The date of the Easter feast was determined at the council of Nicaea in $325 \mathrm{AD}$ (with some specification in 525 and 1582) as Sunday after the first full moon after spring equinox. On this date then depend a lot of other Christian dates like Rose Monday (49 days before Easter if you count also the Easter day), Ascension Day (40 days after Easter if you count also the Easter day), Pentecost (50 days after Easter if you count also the Easter day; hint: "Pente" means fifty) and Feast of Corpus Christi (6o days after Easter).

Because the rhythm of the moon is not consistent with the rhythm of the sun year this date in most Christian churches change between March 22 ${ }^{\text {nd }}$ and April 25 $5^{\text {th }}$. E.g. in 2013 we have had Easter really early on March $31^{\text {st }}$ and in 2014 the Easter Sunday is really late on April 20 ${ }^{\text {th }}$.

Because in the Julian calendar the spring equinox is fixed on the date March $21^{\text {st }}$ and this date is 13 days later than in the Gregorian calendar Easter in the Russian orthodox church has sometimes the same date like Easter in the other Christian churches (when full moon is after April $3^{\text {rd }}$ of Gregorian calendar) and sometimes a date four or five weeks later (when full moon is between March $22^{\text {st }}$ and April $2^{\text {nd }}$ of the Gregorian calendar); but when this date of Easter calculated with Julian calendar coincidences with the Jewish Pesach feast the Russian orthodox Easter is one more week later (so e.g. in 2013).

Problems according to Easter:

- Knowing that on January $1^{\text {st }}$ of 2014 we had new moon (i.e. January $16^{\text {th }}$ was full moon) compute the date of Easter (for the normal church resp. the Russian church) for 2014, 2015 and 2016 by using the average length of an astronomical month. [2014 April 20 ${ }^{\text {th }}$ for all Christian churches $/ 2015$ April $5^{\text {th }}$ resp. actually April $5^{\text {th }}$ but because of Jewish Pesach April $12^{\text {th }} / 2016$ March $27^{\text {th }}$ resp. actually April $24^{\text {th }}$ but because of Jewish Pesach May $\left.1^{\text {st }}\right]$.

- Check these data with the formula of Gauss "Easter $=22+d+e$ " where $d$ is the number of days from March $22^{\text {nd }}$ to full moon and $\mathrm{e}$ is the number of days from full moon to next Sunday. If the number is bigger than 31 the difference to 31 is the date of April. [2014: Spring Moon April 15 $5^{\text {th, }} \mathrm{d}=24, \mathrm{e}=5$, Easter $=$ April 20 ${ }^{\text {th }} / 2015$ : Spring Moon April $4^{\text {th }}, d=13, e=1$, Easter $=$ April $5^{\text {th }} / 2016$ : Spring Moon March $23^{\text {rd }}, \mathrm{d}=1, \mathrm{e}=4$, Easter $=$ March $\left.27^{\text {th }}\right]$.

\section{The Platonic Year}

Because of the spin of the axis of the earth (precession) the direction in space - e.g. at spring equinox - moves very slowly in opposite to the movement of the earth around the sun. For the perspective of the earth this make a rotation of the eclipse around the sun. One revolution of the whole eclipse is called Great Year or Platonic Year and takes 25700 to 25850 years (fuzziness because of fluctuations of the axis of the earth). This fact was already known in the ancient world and from Plato it is known that he found out that 24245 
is the product of the prime numbers $5,7,11$ and 37 . Possibly he thought this is the length of the Great year. Thus the Great year became the name Platonic Year.

The $12^{\text {th }}$ part of it (with about 2150 years) is called a Platonic Month. This is the time one sign of the zodiac moves one month back. Therefore the astrological assumptions made in the ancient Babylon have to be changed back with two signs of the zodiac for today.

Problems in the frame of the Platonic year:

- Prove that 25742 sun years equal to 25741 sidereal years.

$[25742 \cdot 365,2422=9402064,712 / 25741 \cdot 365,25637=9402064,22]$.

- Compute the rotation angle of the eclipse for one year resp. hundred years (using the boundaries 25700 and 25850). How many days does a zodiac sign change in hundred years? [360 : $25700=0.01400778^{\circ}=0.840467^{\prime}=50.428^{\prime \prime}$ and $0.01400778^{\circ} \cdot 100=1.400778^{\circ}=1^{\circ} 24^{\prime} 2.8^{\prime \prime} / 360^{\circ}: 25850=0.0139265^{\circ}=$ $0.83559^{\prime}=50.135^{\prime \prime}$ and $0.0139265^{\circ} \cdot 100=1.39265^{\circ}=1^{\circ} 20^{\prime} 21.4^{\prime \prime}$. Thus the rotation angle in one year is a little bit more than 50 seconds and the average rotation in hundred years is $1.396714^{\circ}=1^{\circ} 23^{\prime} 48.2^{\prime \prime} /\left(1.396714^{\circ}: 360^{\circ}\right) \cdot 365.24219$ $=1.41705$ days $=1 \mathrm{~d}+10 \mathrm{~h}+\mathrm{om}+33 \mathrm{~s}$.$] .$

- For astrology: Look up the zodiacal sign of Albert Einstein who was born 1879 March $14^{\text {th }}$. What zodiacal sign would he have had if he was born at the time of Pythagoras on 550 B.C. March $14^{\text {th }}$ or at the time of Hammurabi on 1775 B.C. March $14^{\text {th }}$ or at the time of Gilgamesh on 2775 B.C. March $14^{\text {th }}$ [Pisces / (2563:100) $\cdot 1.41705$ days $=36.319$ days $\approx 36$ days. Thus in 550 B.C. the zodiac sign Pisces of today goes from January $15^{\text {th }}$ to February $12^{\text {th }}$ and the Aries goes from February $13^{\text {th }}$ to March $15^{\text {th }}$ and Albert Einstein would be in 550 B.C. Aries. / (3788:100) 1.41705 $=53.68$ days $\approx 54$ days (or 18 more). Thus in 1775 B.C. the Aries goes from January $26^{\text {th }}$ to February $25^{\text {th }}$ and Taurus goes from February $26^{\text {th }}$ to March $27^{\text {th }}$. Albert Einstein would be in 1775 B.C. Taurus. / $(4788: 100) \cdot 1.41705=67.85$ days $\approx 68$ days (or 14 days more). Thus in 2775 B.C. Taurus goes from February $12^{\text {th }}$ to March $13^{\text {th }}$ and Gemini goes from March $14^{\text {th }}$ to April $14^{\text {th }}$. Albert Einstein would be in 2775 B.C. just Gemini].

\section{Time zones}

The earth rotates around its axis once in 24 hours so that at points of different longitudes the position of the sun is different. With old solar clocks you sometimes find on a wall the daily time which is determined by the daily maximum altitude of the sun at noon. This astronomical determination of time is called local time.

But since the mid of the $19^{\text {th }}$ century because of the needs for the railway many built-up areas of one country got the same medium time. After some international conferences in 1884 the whole earth was divided in 24 time zones so that from one time zone to the neighbour one the time difference is 1 hour. Because of $360^{\circ}: 24=15^{\circ}$ all $15^{\circ}$ longitudes we have another time zone at which one time zone reaches from the longitude $\mathrm{k} \cdot 15^{\circ} \pm 7 \cdot 5^{\circ}(\mathrm{k}=$ 
$0,1,2, \ldots, 23)$. These exact time zones later on have been modified a little bit so that smaller countries only have one time zone. Also a few counties (Iran, Afghanistan, India, Nepal, Bhutan, Thailand, Middle-Australia, Newfoundland, Suriname) have a time difference to the neighbours time zone of $1 / 2$ hour. The international date line was determined as the longitude of $180^{\circ}$; if at $\mathrm{O}^{\circ}$ (world time) we have $12 \mathrm{o}^{\prime}$ clock noon then from $-172.5^{\circ}$ to $\pm 180^{\circ}$ we have o o'clock and from $\pm 180^{\circ}$ to $+172.5^{\circ}$ we have o o'clock in the morning of the next day. An exception arranged Samoa (west of $180^{\circ}$ ) since 2011, it takes the same day like New Zeeland and Australia (east of $180^{\circ}$ ) because of economical benefit.

Problems in the frame of time zones:

- Compute the longitudes of the boundaries of the time zones. $\left[ \pm 7.5^{\circ}, \pm 22.5^{\circ}, \pm\right.$ $37.5^{\circ}, \pm 52.5^{\circ}, \pm 67.5^{\circ}, \pm 82.5^{\circ}, \pm 97.5^{\circ}, \pm 112.5^{\circ}, \pm 127.5^{\circ}, \pm 142.5^{\circ}, \pm 157.5^{\circ}, \pm$ $\left.172.5^{\circ}\right]$.

- To how many time zones does Australia, Canada, USA, Russia or China extend and how many time zones do have these countries? [Australia: 3 resp. 5 / Canada: 5 resp. 10 / USA: 7 resp. 5 / Russia: 12 resp. 8 (since Sept. 2011, before 10) / China: 5 resp. 1].

- Determine the difference of the local time of Berlin, Cologne, Munich, Rome, Vienna and Warsaw in difference to CET (Central European Time) as well as of Cape Town and Helsinki in difference to EET (East European Time) as well as of New York in difference to EAT (East American Time) as well as of San Francisco in difference to WAT (West American Time). [Berlin: $\approx+3 \mathrm{~min} /$ Cologne: $\approx-32 \mathrm{~min} /$ Munich: $\approx-14 \min /$ Rome $\approx-9 \min /$ Vienna $\approx+6$ Min / Warsaw $\approx+24 \mathrm{~min} /$ Cape Town $\approx-46 \mathrm{~min} /$ Helsinki: $\approx-20 \mathrm{~min} / \mathrm{New}$ York: $\approx+8 \mathrm{~min} / \mathrm{San}$ Francisco: $\approx-10 \mathrm{~min}]$.

- Determine the difference of CET and EAT as well as CET and WAT. What is the time zone of the Cities of the football world cup 2014 in Brasilia?

\section{Addendum}

From a fixed point on the earth and a fixed day one can see sun, moon or the stars turn with a fixed angular velocity on the firmament which is given by $360^{\circ}$ in 24 hours, i.e. $15^{\circ}$ per hour. E.g. if we can see the moon in the East at 9 p.m. then at o o'clock in the night it has turned $45^{\circ}$ and at $6 \mathrm{a} . \mathrm{m}$. in the next morning the moon has turned $135^{\circ}$. i.e. it is near the West.

Because the angle in which we see the sun as well as the moon almost is $1 / 2^{\circ}$ for this angle the sun resp. the moon takes the $30^{\text {th }}$ part of a hour, i.e. 2 minutes. This e.g. means if we see the sun just touching the horizon then in about 2 minutes from this standpoint the sun is totally behind the horizon.

Because in one month the moon turns around the earth in opposite direction the angular velocity of the moon is a little bit smaller than $15^{\circ}$ per hour. We have to subtract 
$360^{\circ}:(29.53059 \cdot 24)$, i.e. $0.508^{\circ}$ per hour; thus the angular velocity of the moon is about $14.5^{\circ}$ per hour.

The motion of the moon $\left(360^{\circ}\right.$ in 29.53 days, i.e. about $12^{\circ}$ per day or $24 \mathrm{~h} \cdot 12 / 360$ per day) causes that moonrise and moonset on average is 50 minutes later from one day to the next one. Also for this reason the tides change on average 50 minutes from one day to the next one.

Knowing that the average distance earth-moon is $384400 \mathrm{~km}$ we can compute the velocity of the moon in the space. Therefore the nearly length of the moon orbit (approximated as circle) is $2 \pi \cdot 384400 \mathrm{~km}$, i.e. $\approx 2415256 \mathrm{~km}$. The time for one revolution (anomalic month) is 27,55 days, i.e. 2380320 s. Thus the mean velocity is $2415256 \mathrm{~km} /$ $2380320 \mathrm{~s}=1,015 \mathrm{~km} / \mathrm{s}$ or about $3650 \mathrm{~km} / \mathrm{h}$.

During its turning around the earth the moon changes its luminescent area that can be seen from the earth (from new moon via full moon to new moon). The question is: How does this luminescent area of the moon change? First of all there are two different answers possible concerning on one hand the area on the moon (seen as part of a globe) and on the second hand the plane area we think we see.

For the full moon the area of the half globe is $2 \cdot \pi \cdot r^{2}$ and the area of the circle (we think we see) is $\pi \cdot r^{2}$. Thus the ratio of both is $1: 2$ (the finest Pythagorean ratio as Martin Wagenschein did say in the 1950s). The same ratio we also find for half-moon.

But how do alter the spatial and plane areas in between? The moon does show us only one half of its surface and the illuminated part we can take as turning constantly by time as wells by angle in respect to the plane perpendicular to the line earth - moon. The curve of the border in an unit globe therefore can be modeled in Analytic Geometry by $\mathrm{x}^{2}+\mathrm{y}^{2}+\mathrm{z}^{2}=1$ and $\mathrm{y}=(\tan \mu) \cdot \mathrm{x}$. The projection of this curve into the $\mathrm{x}$-z-plane then gives us the formula $x^{2}+\left(\tan ^{2} \mu\right) \cdot x^{2}+z^{2}=1$ or $x^{2} /\left(\cos ^{2} \mu\right)+z^{2}=1$ which is an ellipse with north pole and south pole as fixed points and axis in direction of $x$-axis equal to $(\cos \mu)$. From this we can get out that the change of the seen illuminated plane area changes with $(1 / 2+1 / 2 \cdot \cos$ $\mu)$ at which $\mu$ is proportional to the constant changing time. 